\title{
Educação a distância e as Tecnologias: Percepção dos Discentes no Curso de Bacharelado em Administração Pública
}

\author{
Izabelli Lima ${ }^{1}$, Alessandra C. Ceolin ${ }^{2}$, Priscila P. C. Silva ${ }^{3}$ \\ ${ }^{1}$ Graduada (BAP/UFRPE), Recife, PE - Brasil \\ ${ }^{2}$ Professora do Departamento do (DADM/UFRPE), Recife, PE - Brasil \\ ${ }^{3}$ Graduanda (DADM/UFRPE), Recife, PE - Brasil \\ izabellilima@hotmail.com, alessandra.acc@gmail.com; \\ priscila_bceoutlook.com
}

\begin{abstract}
The study analyzes the importance of Information and Communication Technology in the Bachelor's Degree in Public Administration. A questionnaire was applied with 22 questions about the students' personal and academic life. In a sample of $63.24 \%$ of the investigated universe and through an exploratory-descriptive analysis, it was identified that (59.5\%) are female and (52.7\%) are between 26 and 35 years old. The flexible hours (68.9\%) influenced the choice of going the distance. For $68.5 \%$, video classes contributed to learning. The discipline to study (65.8\%) is the biggest challenge and also the evasion of reason (43.2\%). It was concluded that educational technologies provided important changes in distance education.
\end{abstract}

Resumo. $O$ estudo analisa a importância da Tecnologia da Informação e Comunicação no Curso de Bacharelado em Administração Pública. Foi aplicado um questionário com 22 questões acerca da vida pessoal e acadêmica dos discentes. Em uma amostra de 63,24\% do universo investigado e por meio de uma análise exploratória-descritiva, identificou-se que (59,5\%) são do gênero feminino e (52,7\%) possuem entre 26 e 35 anos. A flexibilidade de horário $(68,9 \%)$ influenciou na escolha do curso a distância. Para 68,5\%, videoaulas colaboraram para a aprendizagem. A indisciplina para estudo $(65,8 \%)$ é o maior desafio e também é o motivo de evasão $(43,2 \%)$. Concluiuse que as tecnologias educacionais proporcionaram importantes mudanças na educação a distância.

\section{Introdução}

Na medida em que avançam as Tecnologias da Informação e Comunicação (TIC) e sua utilização, elas facilitam a comunicação, estimulam e colaboram no processo de ensinoaprendizagem, em especial, na educação a distância. A TIC influenciou e vem influenciando fortemente na forma em que as pessoas se comunicam e aprendem [Correia e Santos 2013].

Segundo Vieira (2011), as TICs são elementos norteadores da aprendizagem e potencializam a integração entre as pessoas envolvidas e o conhecimento que se deseja obter. Para Barbosa (2012), as TIC trouxeram novo sentido à Educação a Distância, por 
meio de trocas sociais na proposta pedagógica. Assim, uma das áreas mais favorecidas foi essa nova modalidade de ensino: a educação a distância.

Em 19 de dezembro de 2005, pelo Decreto no. 5.622, que caracteriza a educação a distância como a modalidade educacional na qual a mediação didático-pedagógica nos processos de ensino e aprendizagem ocorre com a utilização de meios e tecnologias de informação e comunicação, com estudantes e professores desenvolvendo atividades educativas em lugares ou tempos diversos (Art. $1^{\circ}$ ) [Brasil 2005].

Para Moran (2012), a TIC é a área que utiliza ferramentas tecnológicas com o objetivo de facilitar a comunicação e o alcance de um alvo comum. A TIC possibilitou o acesso à educação por meios de plataformas de ensino eficazes que garantem a equidade da educação, a qualidade do ensino e aprendizagem e o desenvolvimento pessoal e profissional. De forma abrangente facilita o acesso à educação, a inclusão de pessoas (deficientes ou não) que por diversos motivos não podem estudar de forma presencial, garantindo qualidade do ensino e novas oportunidades.

A mediação pedagógica pode ser realizada pela utilização das diversas ferramentas frequentemente disponibilizadas nos Ambientes Virtuais de Aprendizagem (AVA). Pode ocorrer por meio de uma comunicação síncrona (em tempo real) ou assíncrona (não é em tempo real), possibilitando a participação e o diálogo entre estudantes e professores [Sousa, Sartoti e Roesler 2008]. Desse modo, são utilizadas diversas ferramentas, tais como chats ou bate-papos, fóruns, videoaulas, áudio aulas, podcasts e wikis entre outras.

Segundo Maia e Mattar (2007), a Educação a Distância (EaD) atualmente é praticada em diversos setores: na educação básica, no ensino superior, em universidades abertas, universidades virtuais, treinamento governamentais, cursos abertos, livres, dentre outros. O EaD também promoveu o desenvolvimento científico, criando e utilizando novos métodos e técnicas, oportunizando que os educadores sejam capazes de preparar o aluno para estas ferramentas interativas, facilitando o processo de ensino e aprendizagem.

Maia e Meirelles (2003) salientam que o principal desafio da gestão das TIC nos cursos superiores em EaD é desenvolvimento de linguagem pedagógica apropriada à aprendizagem/ensino por meio do uso das TIC. Esses desafios são: manter os alunos no curso; incentivar a interação entre os alunos e professores; as avaliações devem ser constantes e não estanques somente; ao professor compete o ponto central e mais importante do processo; metodologia EaD deve basear-se no lema "aprender a aprender".

Diante do exposto, o presente artigo investiga sobre a importância da TIC no ensino a distância como ferramenta de aprendizagem, bem como, sobre os motivos e desafios que levam as pessoas a escolherem esta metodologia de ensino. É fato que, no contexto atual, as facilidades da flexibilidade de horários da EaD permitem conciliar os estudos com a rotina profissional, comodidade, pessoas que trabalham em longa jornada, mães que não podem deixar seus filhos em casa, cidades do interior que não possuem instituições públicas ou preço acessível para pagar pelos estudos quando a instituição é privada.

Como o artigo tem como objetivo adquirir informações e dados para melhor analisá-los e, por seguinte, produzir transformações, a discussão sobre inclusão da educação a distância e o uso das novas tecnologias para difundir e estimular suas práticas 
educacionais, reveste-se da importância para o processo de ensino-aprendizagem na qualificação e expansão do ensino superior.

Nesse contexto, a maior produção de estudos e conteúdos sobre o $\mathrm{EaD}$, pode explicitar e desmitificar o preconceito do ensino a distância, promovendo o conhecimento e gerando novas oportunidades, bem como, sua importância na disseminação e aprendizagem do curso de Bacharelado em Administração Pública.

\section{Revisão da Literatura}

\subsection{Processo de Ensino Aprendizagem por meio da Tecnologia}

A sociedade está evoluindo de acordo com a tecnologia, sempre tem algo novo sendo desenvolvido para facilitar o dia a dia; o ser humano sempre procura comodidade, visando o conforto e evitando o desgaste físico e mental.

Neste sentido, Pimenta (2002) educação é a prática social que ocorre nas diversas instancias da sociedade. Seu objetivo é a humanização dos homens, isto é, fazer dos seres humanos participantes dos frutos e da construção da civilização, dos progressos da civilização, resultado do trabalho dos homens. Não há educação a não ser na sociedade humana, nas relações sociais que os homens estabelecem entre si para assegurar a sua existência [Pimenta 2002].

$\mathrm{Na}$ educação a distância, sua integração com diversas ferramentas auxiliam e facilitam o aprendizado. Um sistema de Educação a Distância é formado por todos os processos componentes que operam quando ocorre o ensino e o aprendizado à distância. Ele inclui aprendizado, ensino, comunicação, criação e gerenciamento [Moore e Kearsley 2007].

Segundo Belloni (2006), a interatividade é a característica que uma tecnologia tem ao permitir que o usuário interaja com a máquina. Desse modo, as TIC são o elo fundamental para Educação a Distância, sendo que, em sua ausência, não há a possibilidade de interação entre aluno e professor [Maia 2003; Vieira 2011; Fernandes; Fernandes 2011; Barbosa 2012].

De acordo com Nunes (1994), as Tecnologias Digitais de Informação e Comunicação (TDIC) aplicáveis à EaD levaram alguns estudantes a optarem por essa modalidade, como, por exemplo, a construção autônoma de seu tempo de estudo, o não deslocamento de sua residência para outros espaços, as necessidades constantes de atualizações e capacitações que o mercado de trabalho exige de determinados profissionais e o vasto campo de meios e ferramentas que as novas tecnologias oferecem.

\subsection{O Ambiente Virtual de Aprendizagem (AVA)}

O Ambiente Virtual de Aprendizagem (AVA) faz a mediação da comunicação e da aprendizagem, explorando as potencialidades e funcionalidades de diversas ferramentas que facilitam o processo ensino-aprendizagem.

Dentre estas ferramentas disponíveis no sistema podem-se identificar como assíncronas: os materiais de estudo, fórum, apostilas, artigos, legislações, recomendações de leitura e vídeos. E as ferramentas síncronas como web conferência e chats. No AVA 
da UFRPE pode-se dispor de todas estas ferramentas, professores e tutores; além de aulas presenciais para acompanhar o processo de aprendizagem.

Contrariando as pessoas que não conhecem a metodologia de estudo $\mathrm{EaD}$, o processo de ensino aprendizagem não é solitário [Moran 2007]. Surgem em torno dele, atores que o auxiliam nesse processo, acompanhando e supervisionando suas ações. Entre eles professores especialistas/pesquisadores e tutores responsáveis em organizar o material didático básico para a orientação do aluno. A equipe técnica que o auxilia na produção do material, como revisores de texto, técnicos em informática, designers gráficos e a equipe de coordenação e orientação pedagógica do curso.

Com isso, vale ressaltar, utilização da Educação à distância como ferramenta de apoio à aprendizagem capaz de qualificar e preparar o Administrador Público de forma efetiva sem comprometer ou reduzir a qualidade do ensino superior.

\section{Metodologia}

Para a definição de universo pode-se delimitar o campo de pesquisa em termos temporais, geográficos, setoriais ou qualquer outra dimensão cabível, com base na disponibilidade ou obtenibilidade de dados ou com o fundamento nos objetivos e nos custos da execução da pesquisa [Leite 1978]. Trata-se de uma pesquisa exploratória e descritiva que possui o objetivo de compreender quais ferramentas tecnológicas mais estão associadas à aprendizagem no curso de Bacharelado em Administração Pública da UFRPE.

De acordo com Richardson (1999), p. 190 "geralmente os questionários cumprem pelo menos duas funções: descrever as características e medir determinadas variáveis de um grupo social".

O universo dessa pesquisa engloba a relação de todos os graduandos do Bacharelado em Administração Pública, identificando o perfil dos estudantes e sua interação com as TIC. Hoje, o curso de Bacharelado em Administração Pública conta com 117 discentes matriculados em 3 polos de ensino (Recife, Limoeiro, Carpina).

Para a coleta de dados foi desenvolvido um questionário semiestruturado, contendo questões abertas e fechadas, buscando compreender: o perfil dos discentes de administração pública da UFRPE, as ferramentas tecnológicas disponíveis para o ensino - aprendizagem, quais ferramentas proporcionam maior aprendizado no $\mathrm{EaD}$ e as principais vantagens e desafios em fazer um curso EaD e sua relação com as TIC.

O questionário possui 22 questões e foi enviado via internet para os 117 discentes matriculados no curso, em três polos pesquisados (Recife, Limoeiro e Carpina). O questionário foi aplicado no início do mês de junho de 2019 e houve um retorno de 74 respostas, o que corresponde a $63,24 \%$ do universo investigado.

Além do questionário, a coleta de dados também ocorreu por meio de pesquisas em materiais já publicados, compostos por livros, revistas, artigos científicos e por informações especializadas em sites a fim de compreender a inserção da educação à distância no Brasil. A análise de dados foi realizada utilizando planilhas eletrônicas para realização de tabelas e gráficos. 


\section{Resultados}

Os resultados encontrados estão dispostos em cinco seções. A primeira trata dos inserção e aumento da educação à distância no Brasil, considerando o material bibliográfico sobre o tema. Da segunda à quinta seção estão dispostos os resultados obtidos a partir da percepção os respondentes.

\subsection{Sobre a Educação à Distância no Brasil}

No Brasil, a educação a distância teve um aumento expressivo a partir de 2005, principalmente no ensino superior, confirmando sua expansão pelo o número de matrículas entre o período de 2005 a 2009, com o ritmo ligeiramente inferior em 2010, ano que $14,6 \%$ do total de matrículas no país correspondiam à modalidade $\mathrm{EaD}(390.179$ matrículas). Destas, 19,5\% representavam as vagas no setor público [Mec 2012].

Esta expansão no setor público deve-se à criação de um dos maiores sistemas de acesso à educação superior no país a partir do sistema Universidade Aberta do Brasil (UAB), constituindo-se numa oportunidade de aprendizado capaz de trazer impactos positivos para a sociedade por meio do acesso ao mundo do conhecimento [Arieira et al. 2009; Gatti 2008; Matias-Pereira 2008; Segenreich 2003].

Uma política pública instituída pelo Ministério da Educação em 2005, a partir da articulação entre a Secretaria de Educação a Distância do Ministério da Educação (SEED/MEC), a Diretoria de Educação a Distância (DED) e a Coordenação de Aperfeiçoamento de Pessoal de Nível Superior (DED/CAPES), a qual buscou desenvolver a modalidade EAD a partir da articulação de instituições federais, estaduais e municipais, além dos institutos de educação tecnológica, para expandir a educação superior no país [Uab/Capes 2013; Segenreich 2000; Melo; Melo e Nunes 2009].

O sistema UAB "não se constitui formalmente como uma unidade de ensino, e sim um órgão do MEC articulador das instituições públicas, responsáveis pela oferta de cursos superiores na modalidade à distância" [Costa 2007]. Logo, o sistema UAB não possui uma estrutura física propriamente dita, funcionando em parceria com prefeituras e instituições de ensino que, de forma autônoma, oferecem cursos e as estruturas físicas necessárias para a sua implantação [Sembay 2009].

A ampliação da educação à distância por meio de estruturas de redes pode ser explicada pelo amadurecimento das IES públicas em mecanismos de cooperação, pelo uso das tecnologias da informação e comunicação (TIC) que permitem romper limitações de tempo ou de lugar e pela construção de relacionamentos horizontais entre diferentes atores de forma dinâmica e articulada [Uab/Capes 2013; Maia e Meirelles 2002; Nohria 1992].

\subsection{Perfil dos Discentes de Administração Pública da UFRPE}

O questionário realizado é composto de 22 questões acerca da vida pessoal, familiar e social dos alunos, suas trajetórias escolares, o uso das tecnologias educacionais e uma pequena avaliação sobre as perspectivas para o futuro. Em um universo de 117 discentes, em três polos pesquisados (Recife, Limoeiro e Carpina), 74 alunos responderam ao questionário. A maior parte dos respondentes é do polo Limoeiro (27), seguido por 
discentes do polo Recife (25) e do polo Carpina (22), perfazendo um total de 74 respondentes. Destes, a maioria $(59,5 \%)$ é do gênero feminino.

Ao analisar a faixa etária dos respondentes, verifica-se que a maioria possui entre 26 a 35 anos (52,7\%), 20,3\% possuem até 25 anos, seguido por 17,6\% que possui entre 36 a 45 anos e $9,5 \%$ possuem de 46 a 55 anos. Nenhum discente possui mais de 56 anos, mas é possível verificar uma heterogeneidade de idade, que pode influenciar positivamente nas percepções e no aprendizado, considerando que há pessoas com vivência e experiência de mercado, outros jovens que podem colaborar com a visão mais atual de uso de tecnologias, dentre outros fatores que são positivos.

Ao analisar a distância da residência e do polo onde o discente cursa administração pública, verifica-se que 45,9\% moram na cidade do Polo. Outros 21,6\% moram em cidades vizinhas que ficam até $20 \mathrm{~km}$, mas há um grupo de alunos $(32,5 \%)$ que residem distantes pelo menos $21 \mathrm{~km}$ do polo onde estudam. Vale considerar esse esforço dos discentes, uma vez que o curso é semipresencial, com aulas e provas sendo aplicadas presencialmente no polo.

Analisando a composição familiar, verifica-se que os discentes moram com cônjuge $(47,3 \%)$, com os pais $(25,7 \%)$, com familiares $(14,9 \%)$, sozinho $(8,1 \%)$ e o restante mora com amigos. A maioria dos discentes não possui filhos $(63,5 \%)$. Esses resultados podem estar atrelados a faixa etária dos discentes que ainda estão buscando caminhos profissionais para depois constituir família.

Observa-se que o rendimento dos respondentes é, em sua maioria, de até 2 salários mínimos (63,9\%), sendo que 37,5\% possuem renda de 1 a 2 salários mínimos e 26,4\% até 1 salário mínimo. Nesse sentido, observa-se que a universidade pública é muito importante para esses discentes, pois dificilmente poderiam cursar uma universidade particular. Para Mancebo, Vale e Martins [2015], uma das marcas da expansão em curso no país refere-se ao uso do EAD, que vem sendo concebido como uma modalidade privilegiada para promover a democratização, bem como a expansão do ensino e até para alavancar a transformação social via educação.

O meio de transporte mais utilizado para ir até o polo para aulas e provas é o transporte coletivo $(45,9 \%)$. Observa-se que a maioria dos estudantes, cursaram seus estudos de forma integral em escola pública $(56,8 \%)$, sendo que $23 \%$ cursou parte em escola pública e parte em escola privada. Apenas 20,3\% cursaram integralmente em escolas particulares seus estudos antes de serem discentes do curso de Administração pública da UFRPE.

Quanto aos motivos que fizeram com que os discentes optassem pelo curso de Administração Pública, tem como resultado, prestar concurso público $(55,4 \%)$ foi o que motivou esses respondentes a escolher o curso. Já, 36,5\% tem a pretensão de cursar pósgraduação. Outras aspirações tiverem menor influência na escolha do curso.

Quando questionados sobre o uso de ferramentas no processo de aprendizagem antes de entrar no curso de graduação, verifica-se que 41,9\% dos discentes já utilizavam as ferramentas no processo de aprendizagem, seguido por 31,1 que utilizavam para redes sociais e para aprendizagem. Já, 20,3\% utilizavam apenas como ferramenta de comunicação e interação.

\subsection{Motivos e desafios dos Discentes de Administração Pública da UFRPE}


Quando questionados o motivo pela escolha do curso EAD, a flexibilidade de horário $(68,9 \%)$ foi o fator determinante na escolha. A oportunidade de estudo também foi citada por $17,6 \%$ dos respondentes e para $12,2 \%$ a razão foi o da qualidade da instituição.

Entre as vantagens em escolher o curso está atuar em atividades com políticas públicas (36,5\%). No questionário foi listado qual a sua maior dificuldade para adaptação do curso e $68,9 \%$ informou que a rotina e o prazo nas entregas das atividades. Também foram citadas a elaboração de atividades $(18,9 \%)$ e a utilização do AVA $(8,1 \%)$. Outros fatores também foram citados.

Ter disciplina $(65,8 \%)$ é o maior desafio nesta metodologia de ensino, na percepção dos discentes. $21,7 \%$ dos discentes afirmam que o maior desafio é ter autonomia para estudar. No entanto, 9,6\% dos discentes comentam sobre a baixa socialização. Outros fatores também foram citados em menor escala.

Entre as opções, na visão dos respondentes, a videoaula gravada representou $68,5 \%$ como a ferramenta que mais poderia colaborar no processo de aprendizagem. Essa informação pode representar um direcionamento nas próximas ações da coordenação do curso em direção a melhoria contínua.

Para $17,8 \%$ dos respondentes a realização de cursos de extensão para elaborar atividades pode ser importante também. Videoaulas explicando as ferramentas do AVA também podem colaborar. Nesse sentido, verifica-se que há uma parcela de alunos do curso que possui dificuldades na utilização das ferramentas disponíveis no AVA.

Verifica-se que a diversidade dos formatos de mídia é ferramenta mais citada pelos respondentes $(41,1 \%)$. Outros $32,9 \%$ afirmam a importância no contato próximo via AVA, na relação professor/tutor/alunos. Para 19,2\% a interação e retornos rápidos são citados pelos respondentes.

Ainda que já tenham conhecimento na necessidade de autonomia nos estudos no EAD; eles citam que o principal motivo de evasão (desistência do curso) é a falta de disciplina $(43,2 \%)$ e isso constitui uma característica da metodologia de ensino. $25,7 \%$ citam que é a espera por retornos e correções, $13,5 \%$ relatam que são os problemas com a utilização de recursos. Vários outros fatores foram apontados em menor escala, como falta de identificação com o curso, poucos recursos interativos, falta de motivação e interação com os docentes.

Para Souza, Sartori e Roesler (2008), a EAD está inserida num processo ativo, em constante movimento, num espaço repleto de elementos objetivos e subjetivos. Alunos e professores desenvolvem formas de relacionamento, de comunicação, de ensino e de aprendizagem diferentes do presencial, mas buscam a segurança e confiabilidade.

\subsection{Regularidade dos Discentes de Administração Pública da UFRPE}

Além dos dados levantados pela presente pesquisa, são apresentados que apenas $25,67 \%$ irão concluir o curso dentro do período regular. Dentre as dificuldades ocasionadas foram relatados problemas pessoais (saúde e trancamento de semestre), reprovação de disciplinas, falta de regularidade na oferta de disciplinas (reoferta) e dificuldades na realização do TCC.

É interessante observar não só a evasão escolar, pois a oferta de vagas nos polos Recife, Carpina e Limoeiro que ingressaram através do Edital $\mathrm{n}^{\circ}$ 25/2015 (semestre 2015.2) foram 50 alunos por polo. Hoje destes que entram nesta oferta estão matriculados 
em Recife 40 alunos (destes 11 alunos iniciaram em 2015.2), em Limoeiro 25 alunos (24 alunos iniciaram em 2015.2) e Carpina 54 alunos (23 alunos iniciaram em 2015.2), mas também o deslocamento dos discentes para o polo que estão matriculados, a solicitação de transferência entre polos e os portadores de diploma.

\subsection{UFRPE como provedora de conhecimento aos Discentes de Administração Pública}

As informações demonstram que o curso de Administração Pública da UFRPE vem promovendo o conhecimento necessário para gerar novas oportunidades. As tecnologias como facilitadoras deste processo e pertencente ao futuro da educação, desmistificando o preconceito do ensino a distância.

$\mathrm{Na}$ visão dos respondentes, o curso possui excelente qualidade, materiais de apoio e professores qualificados que promovem a qualidade de ensino. Relatam também a importância do tutor presencial e da organização do polo para integralizar com a Universidade.

Entre as sugestões de melhorias neste processo estão: a) organização de informações no sistema; b) cumprimento nos prazos as respostas dos discentes no AVA e nas postagens das notas de atividades e avaliações; c) videoaulas gravadas no ambiente virtual; d) cursos de extensão que favoreçam e auxiliem nas atividades acadêmicas propostas, e; e) maior diversidade de atividades a fim de estimular o interesse do aluno.

\section{Considerações Finais}

Visto que a sociedade hoje está inserida no mundo tecnológico e globalizado, faz-se necessário encontrar meios para inserir a população nesse mundo derrubando as barreiras sociais vigentes, democratizando o ensino e o acesso ao ensino superior. A educação à distância $(\mathrm{EaD})$ tem se mostrado um importante mecanismo de difusão do conhecimento e democratização da informação, ainda mais no cenário brasileiro, no qual a maioria dos municípios não tem acesso à educação superior e ela emerge como uma alternativa para preencher essa lacuna [Maia 2007].

A Educação a Distância pode ser considerada a mais democrática das modalidades de educação, pois se utilizando de tecnologias de informação e comunicação transpõe obstáculos à conquista do conhecimento [Moran 2009]. Considerando que é necessário associar outras propostas tecnológicas que vem surgindo, visando as práticas de interação sociocultural uma vez que os estudos abrangentes são de extrema importância e requer atualizações, pois não se esgotam aqui.

Nesse sentido, funciona como um eficaz instrumento para a universalização do acesso ao ensino superior, minimizando a concentração de oferta de cursos de graduação nos grandes centros urbanos e evitando o fluxo migratório para as grandes cidades. Percebe-se a importância frente ao crescente aumento que a educação a distância tem apresentado no país [Mec 2012], dados demonstram a necessidade de uma articulação mais intensa do sistema UAB, para atingir um maior número de municípios, seja na maior participação das instituições de ensino, no maior envolvimento das prefeituras e principalmente na ampliação de ofertas dos cursos para que, de fato, atinja seu objetivo de democratizar ao acesso à educação superior.

A tecnologia da informação é sem dúvida capaz de prover através de suas ferramentas, estimulando o processo de aprendizagem. Atingindo o objetivo de 
democratizar ao acesso à educação superior e assim contribuir na formação acadêmica do Administrador Público. Vale ressaltar a importância de explorar na educação a distância novas interações, atividades e ações educacionais a fim de incentivar uma "educação sem distância" [Tori 2010].

Nesse sentido, verifica-se que, na percepção dos discentes, o curso de Bacharelado em Administração Pública da UFRPE vem promovendo aos discentes uma educação pública, gratuita, de qualidade e transformadora, contribuindo para os alunos mudarem suas vidas e as qualificando para o mercado de trabalho, através de uma política pública de educação a distância. Também cabe ressaltar, a contribuição da universidade por meio da interiorização da universidade para diminuir as desigualdades de um país tão injusto e garantir o ingresso de pessoas residentes no interior do Estado na educação superior. Neste contexto, pode-se concluir que as tecnologias educacionais proporcionaram importantes mudanças na educação a distância e na inclusão social.

\section{Referências}

Barbosa, C. M. A. M. (2012). A aprendizagem mediada por TIC: interação e cognição em perspectiva. Faculdade de Ensino Superior Dom Bosco. RBAAD-Associação Brasileira de Educação a Distância, (11), 84-100.

Belloni, M, L. (2003). Educação a distância. Autores Associados. $3^{\text {a }}$ ed. Campinas.

Brasil. (2005). Decreto no. 5.622 de 19/12/2005. Diário Oficial da União, 20/12/2005. Disponível em: $<$ https://www2.camara.leg.br/legin/fed/decret/2005/decreto-5622-19dezembro-2005-539654-publicacaooriginal-39018-pe.html>. Acesso em: 20 abr. 2019.

Correia, R. L. e Santos, J. G. A (2013). Importância da Tecnologia da Informação e Comunicação (TIC) na Educação a Distância (EaAD) do Ensino Superior (IES). Revista Aprendizagem em EaD.(2), 1-16.

Fernandes, A. P. L. M. e Fernandes, R. R. (2012) A Importância das TICs como Recurso Didático no Ensino da Matemática Financeira. Simpósio de Excelência em Gestão e Tecnologia: gestão, inovação e tecnologia para sustentabilidade. IX SEGeT 2012, 110 .

Leite, J. A. A. (1978). Metodologia de Elaboração de Teses. São Paulo: Editora McGrawHill do Brasil.

Maia, C.; J. e Mattar. (2007). ABC da EaD: a Educação a Distância hoje. 1. ed. São Paulo: Pearson.

Maia, M. de e Meirelles, F. de S. (2003). Educação a Distância e o Ensino e o Ensino Superior no Brasil. Revista Brasileira de Aprendizagem Superior no Brasil Aberta e a Distância, São Paulo, 1-19.

Mancebo, D; Vale, A. A. e Martins, T. B. (2015). Políticas de Expansão da Educação Superior do Brasil 1995-2010. Revista Brasileira de Educação. 20(60).

Moore, M. G.; e Kearsley, G. (2008). Educação a distância: uma visão integrada. Tradução Roberto Galman. São Paulo: Cengage Learning.

Moran, J. M. (2007). A educação que desejamos: novos desafios e como chegar lá. Campinas: Papirus. 
Moran, J. M. (2019). O que é Educação a Distância. Universidade de São Paulo. Disponível em: $\quad<$ http://www.eca.usp.br/moran/wpcontent/uploads/2013/12/dist.htm>. Acesso em: 29 jan. 2019.

Moran, J. M., Massetto, M. T. e Behrens, M. A. (2012). Novas tecnologias e mediações pedagógicas. Campinas, SP. Papirus.

Nunes, I. B. (1994). Noções de Educação a Distância. Disponível em: $<$ http://pt.scribd.com/doc/21015548/Artigo-1994-Nocoes-de-Educacao-a-DistanciaIvonio-Barros-NUNES>. Acesso em: 31 mar. 2019.

Nunes, I. B. (2009). A história da EaD no mundo. IN: LITTO, Frederic, FORMIGA, Marcos (orgs.). Educação a distância: O estado da Arte. Ed: ABEB.

Pimenta, S. G. (2002). O estágio de professores: unidade, teoria e prática? 5.ed. São Paulo: Cortez.

Mec. (2012). Portal do Ministério da Educação. Universidade Aberta do Brasil. Disponível em: $<$ http://portal.mec.gov.br/uab $>$. Acesso em 28 jan. 2020.

Portal Mec.Universidade Aberta do Brasil. Disponível em: $<$ http://portal.mec.gov.br/component/tags/tag/32123>. Acesso em 26 maio. 2019.

Richardson, R. J. (1999). Pesquisa social: métodos e técnicas. São Paulo: Editora Atlas.

Segenreich, S. C. D. (2009) ProUni e UAB como estratégias de EaD na expansão do Ensino Superior. Pro-Posições, Campinas, 20, 2 (59), 205-222.

Souza, A. R. B.; Sartori, A. S. e Roesler, J. (2008). Mediação Pedagógica na Educação a Distância: entre enunciados teóricos e práticas construídas. Rev. Diálogo Educ., Curitiba, 8 (24), 2008. 327-339.

Tori, R. (2010). Educação sem distância: as tecnologias interativas na redução de distâncias em ensino e aprendizagem. São Paulo: Editora Senac.

Vieira, R. S. (2011). O papel das tecnologias da informação e comunicação na educação: um estudo sobre a percepção do professor/aluno. Disponível em: $<$ http://seer.abed.net.br/edicoes/2011/Artigo_05.pdf>. Acesso em: 28 fev. 2020. 